\title{
Airborne direct-detection and coherent wind lidar measurements along the east coast of Greenland in 2009 supporting ESA's Aeolus mission
}

\author{
Uwe Marksteiner $^{\mathrm{a}}$, Oliver Reitebuch ${ }^{\mathrm{a}}$, Stephan Rahm ${ }^{\mathrm{a}}$, Ines Nikolaus ${ }^{\mathrm{b}}$, Christian Lemmerz ${ }^{\mathrm{a}}$, \\ Benjamin Witschas ${ }^{\mathrm{a}}$ \\ ${ }^{a}$ Deutsches Zentrum für Luft- und Raumfahrt, Institut für Physik der Atmosphäre, Oberpfaffenhofen, \\ 82234 Wessling, Germany; \\ ${ }^{\mathrm{b}}$ Physics Solutions, Oberdorfer Str. 20, 82278 Althegnenberg
}

\begin{abstract}
The Aeolus mission of the European Space Agency (ESA) will send the first wind lidar to space to fulfill the utmost need for global wind profile observations. Before the scheduled launch in late 2013, pre-launch campaigns have to be performed to validate the measurement principle and to optimize retrieval algorithms. Therefore, an airborne prototype instrument has been developed, the ALADIN Airborne Demonstrator (A2D). In September 2009 an airborne campaign over Greenland, Iceland and the Atlantic Ocean was conducted using two instruments: the A2D and a well established coherent $2-\mu \mathrm{m}$ lidar for aerosol and cloud backscatter. Thus, two wind lidar instruments measuring Mie and Rayleigh backscatter in parallel were operated on the same aircraft.

This paper describes the analysis of wind measurement data gathered during a flight segment on 26.09.2009. A dedicated aerial interpolation algorithm is introduced taking into account the different resolution grids of the two lidar systems. Via a statistical comparison of line of sight (LOS) winds the systematic and random error of the direct-detection wind lidar A2D was assessed, yielding $-0.7 \mathrm{~m} / \mathrm{s}$ and $1.9 \mathrm{~m} / \mathrm{s}$ for the Rayleigh and $1.1 \mathrm{~m} / \mathrm{s}$ and $1.3 \mathrm{~m} / \mathrm{s}$ for the Mie channel, respectively.
\end{abstract}

Keywords: ADM-Aeolus, wind lidar, ALADIN

\section{INTRODUCTION}

In 1999 the Atmospheric Dynamics Mission ADM-Aeolus was selected as the $2^{\text {nd }}$ Earth Explorer Core Mission within the European Space Agency's (ESA) Living Planet Programme and it is considered as a technology demonstrator for future operational wind lidar missions. After launch in late 2013 Aeolus will be the $1^{\text {st }}$ European lidar and the first wind lidar worldwide in space. The measurement of wind is considered to be a preferential objective by the World Meteorological Organisation (WMO) [1]. A spaceborne Doppler lidar is considered to be the only candidate to provide a global coverage of wind profile observations essential for the improvement of Numerical Weather Prediction (NWP) and advancement of climate studies. Currently a lack of coverage is present especially over the oceans which contribute with about two thirds to the earth surface. With its global vertical wind measurements Aeolus will contribute to closing this gap which has been identified as one of the main deficiencies of the Global Observing System (GOS). In impact studies it was shown that wind measurements can considerably improve medium-range weather forecast [2]. Due to their small representativeness and instrumental errors, measurements from wind lidars have high potential to reduce the analysis error of NWP models in data-sparse regions [3].

Aeolus will revolve the earth at an altitude of $400 \mathrm{~km}$ in a sun-synchronous dawn-dusk orbit with a $35^{\circ}$ off-nadir and across track viewing geometry [4]. During its planned three-year life time the satellite will measure wind from $0-27 \mathrm{~km}$ in troposphere and lower stratosphere with an adaptable resolution. The single layers of the measurement grid can be commanded from 250 to $2000 \mathrm{~m}$ vertical thickness aiming at the extraction of the most valuable data from the occurring atmospheric conditions, e.g. in case of high cirrus clouds, varying ground elevation or in order to distinguish dust layers from the underlying planetary boundary layer. The satellite carries the Atmospheric Laser Doppler Instrument (ALADIN), an active instrument firing laser pulses towards the atmosphere. ALADIN is equipped with two interferometers sensitive to molecular and aerosol or cloud backscatter, assuring optimal coverage within the whole altitude range.

Lidar Technologies, Techniques, and Measurements for Atmospheric Remote Sensing VII, edited by Upendra N. Singh, Gelsomina Pappalardo, Proc. of SPIE Vol. 8182, 81820J

(c) 2011 SPIE $\cdot$ CCC code: $0277-786 X / 11 / \$ 18 \cdot$ doi: $10.1117 / 12.897528$

Proc. of SPIE Vol. 8182 81820J-1 
Along with the development of Aeolus and the integration of ALADIN into the satellite, progression also took place in the field of wind retrieval algorithms. Here, the main focuses lay on increasing the flexibility of processing tools and reliably detecting complex, inhomogeneous atmospheric conditions. The resulting software will be applied not only by ESA's operational ground segment but also by the numerical weather prediction centers [5].

As part of a risk reduction programme an existing prototype instrument of ALADIN, the ALADIN Airborne Demonstrator (A2D), has been employed up to now in several ground and airborne campaigns that support pre-launch validation and optimization of measurement principles, performance and algorithms. The A2D is the $1^{\text {st }}$ direct-detection Doppler lidar to be operated from an aircraft in a viewing geometry comparable to the Aeolus satellite. ALADIN and the A2D both are using novel combinations of techniques that have never been implemented in a wind lidar before, e.g. a sequential arrangement of a Fizeau- and a double-edge Fabry-Perot spectrometer. Extensive research has been dedicated to describe the interaction of this optical arrangement with atmospheric signals [6][7][8][9]. The A2D is working in the ultraviolet region at $355 \mathrm{~nm}$ analysing narrowband Mie backscatter from aerosols and clouds and broadband Rayleigh backscatter from molecules, respectively, with its two dedicated interferometers.

During an airborne campaign undertaken by DLR in September 2009, the A2D and a commercial and modified 2- $\mu \mathrm{m}$ wind lidar (Lockheed Martin, DLR) were flown together successfully. The A2D and the $2-\mu \mathrm{m}$ lidar retrieve wind information from the Doppler shift of the collected backscatter signal with respect to the initially transmitted laser pulse frequency. Line of sight (LOS) wind fields from the A2D Rayleigh and Mie channel as well as from the 2- $\mu \mathrm{m}$ wind lidar will be presented from a flight leg along the east coast of Greenland from September 2009 (Figure 1, right, red line).

All flight tracks of the airborne campaign lasting from 16.09.2009-01.10.2009 are shown in Figure 1, left. Two calibrations were performed on 21.09.2009 within one hour over the Greenland ice shield under constant atmospheric and cloud free conditions. During a second flight from Keflavik (Iceland) to Kangerlussuaq (Greenland) on 26.09.2009 a continuous wind measurement of 30 minutes (corresponding to about $370 \mathrm{~km}$ ) was carried out along the east coast of Greenland. It is the first time that wind profiles from an airborne direct-detection Doppler lidar were obtained.

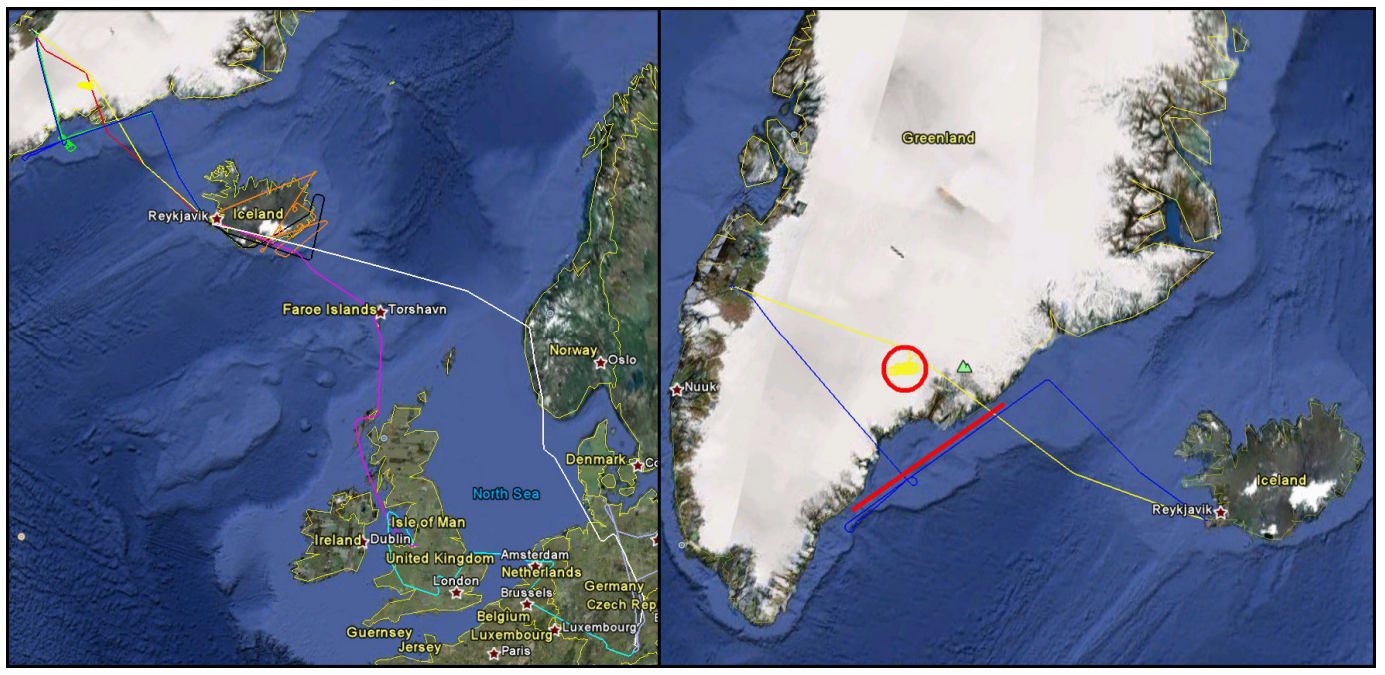

Figure 1. left: tracks of all flights of the airborne campaign during 16.09.2009 - 01.10.2009, right: flight track from 21.09.2009 (yellow) containing two calibrations (red circle) over the Greenland ice shield and a flight track from 26.09.2009 (blue) containing a continuous wind measurements scene (red line) along the east coast of Greenland.

\section{INSTRUMENT DESPCRIPTION}

The A2D laser emits short light pulses in the ultraviolet into the atmosphere. The light backscattered towards the A2D is collected by a $20-\mathrm{cm}$-telescope, spectrally resolved by the interferometers and time gated in order to get a subdivision in vertically arranged atmospheric layers of $250-2000$ m selectable range thickness. Within the A2D instrument the beam is distributed onto two spectrometers, i.e. a Fizeau interferometer for detection of narrowband particle backscatter (Mie) and a double-edge Fabry-Perot interferometer for detection of broadband molecular backscatter (Rayleigh) [8]. The latter allows measuring the intensity transmitted through its two filters A and B located on either side of the Rayleigh-Brillouin [7] shaped backscatter signal via an accumulative charged couple device (ACCD). If compared to Aeolus, the A2D 
configuration features a coaxial transmitter-receiver arrangement instead of a transceiver telescope. Among others differences are also present in terms of Field of View and sensing range and hence in the signal dynamics [10].

Validation of the instrument, its measurement principle and the performance models currently in use are a crucial part of the pre-launch preparation phase, wherein ground processing, calibration procedures and quality-control algorithms were optimized. This necessitates, for example, the collection of data sets retrieved under different or varying atmospheric scenes. Thus, the A2D has been deployed in various pre-launch campaigns. Preparatory work has been put into the laser, especially regarding line width and short term frequency stability [11]. The frequency of single laser pulses proved to be stable even in aircraft environment including vibrations [8]. Under participation of several other instruments including a windprofiler, radiosondes and the $2-\mu \mathrm{m}$ lidar, comparative measurements took place during two ground campaigns in 2006 and 2007 [9]. Radiometric performance models were assessed during a ground campaign by comparing measurements to results obtained from an A2D simulator [7]. In further investigations special emphasis has been laid onto the determination of the shape of the Rayleigh Brillouin scattering spectrum [12][13][14].

During an airborne campaign in September 2009 the A2D was measuring wind profiles in parallel to the well established $2-\mu \mathrm{m}$ lidar [3][15]. With its heterodyne measurement principle it also has a different approach than foreseen for the A2D and the Aeolus satellite. If operated in a fixed viewing geometry, i.e. pointing direction of laser and telescope, both lidars are restricted to the detection of LOS wind components. Additionally, the $2-\mu \mathrm{m}$ lidar can be operated in a scanning mode, enabling it to measure 3-dimensional wind vector profiles. In contrast to the constant A2D LOS the 2- $\mu \mathrm{m}$ lidar was operated in a "step \& stare" mode where a conical VAD (Velocity Azimuth Display) scan of 20 azimuthal positions with 500 laser pulse returns each corresponds to one observation. Table 1 gives a comparative overview of some main features of the two lidars.

Table 1. System description: requirements and features of the A2D and the 2- $\mu \mathrm{m}$ lidar with respect to the configuration used during the presented wind measurements

\begin{tabular}{|llll|}
\hline & \multicolumn{1}{c}{ A2D } & \multicolumn{1}{c}{$2-\mu \mathrm{m}$} \\
\cline { 1 - 2 } Type & direct- detection & heterodyne \\
Transmitter & Nd:YAG, tripled & Tm:LuAG \\
Wavelength & $355 \mathrm{~nm}$ & $2.022 \mu \mathrm{m}$ \\
Energy / pulse & $60 \mathrm{~mJ}$ & $1.5 \mathrm{~mJ}$ \\
Repetition rate & $50 \mathrm{~Hz}$ & $500 \mathrm{~Hz}$ \\
Pulse length & $<25 \mathrm{~ns}(\mathrm{FWHM})(=50 \mathrm{MHz})$ & $400+/-40 \mathrm{~ns}$ (FWHM) \\
Telescope aperture & $200 \mathrm{~mm}$ & $108 \mathrm{~mm}$ \\
Nadir angle & $20^{\circ}$ & $20^{\circ}(\mathrm{scanning}$ around nadir $)$ \\
Vertical resolution & $296 \mathrm{~m}$ & $100 \mathrm{~m}$ \\
Horizontal resolution & $\sim 3.8 \mathrm{~km}(18 \mathrm{~s})$ & $\sim 6.8 \mathrm{~km}$ (32 s) \\
Spectrometers & molecular \& aerosols / cloud particles & aerosols / cloud particles \\
\hline
\end{tabular}

\section{AIRBORNE CAMPAIGN OVER ICELAND, GREENLAND AND NORTH ATLANTIC}

In contrast to the Aeolus Ground Campaigns conducted before, the 2009 airborne campaign aimed on the validation of instrument and performance models from a downward looking geometry, i.e. from aircraft, which allows the retrieval of data that cannot be obtained from ground measurements. In this respect, for example new insights were revealed by investigations not only on ground return processing and ground albedo properties but also on sea surface and sub-surface reflectance [16]. The goal of the 2009 campaign was to perform spectrometer response calibrations, assessing quality of wind measurements and statistical errors and getting new insights into the handling of quality control and correction schemes for different atmospheric conditions, regarding e.g. inhomogeneous cloud cover and aerosol loading. Keflavik, Iceland, was chosen as the basis of the campaign of which two flights are sketched in Figure 1, right. In total a number of 10 flights were conducted using the DLR Falcon aircraft. 


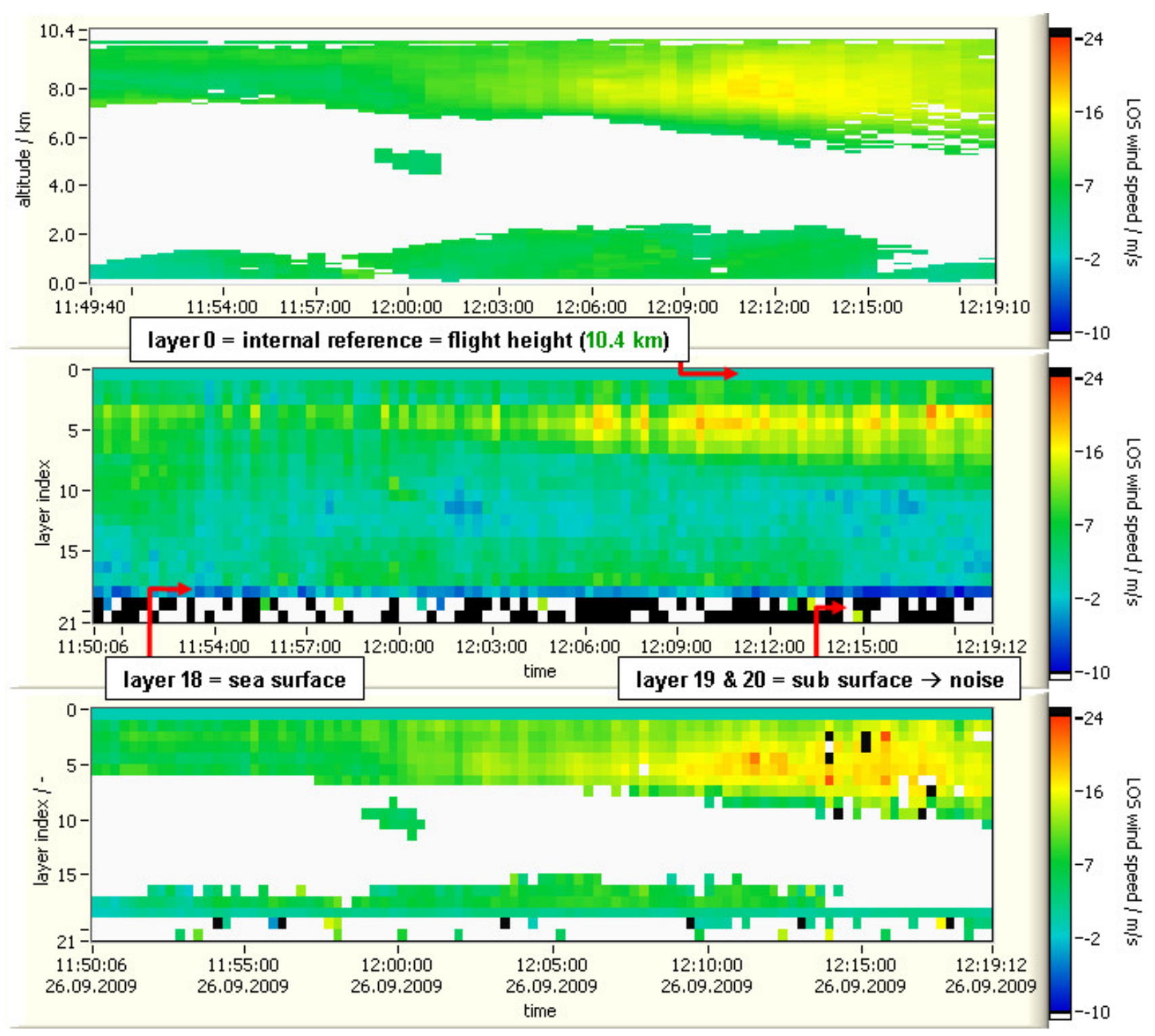

Figure 2. Top: LOS wind profile measured with the 2- $\mu \mathrm{m}$ lidar on 26.09.2009. Valid data is present between 10 to 6 $\mathrm{km}$ and $3 \mathrm{~km}$ to ground. White colour in the atmosphere corresponds to missing or very low aerosol signal; a cloud return is visible at around $5 \mathrm{~km}$ at 12:00;

Middle: Rayleigh LOS wind profile measured with the A2D on 26.09.2009 bordered by layer 0 showing the signal of the internal reference at the aircraft flight altitude of $10.4 \mathrm{~km}$ and layer 18 wherein the ground was found. Strong winds with up to $24 \mathrm{~m} / \mathrm{s}$ LOS velocity are indicating a part of the jet-stream on the upper right;

Bottom: Mie LOS wind measured with the A2D on 26.09.2009 bordered by layer 0 showing the signal of the internal reference at the aircraft flight altitude of $10.4 \mathrm{~km}$ and layer 18 wherein the ground was found. White colour in the atmosphere corresponds to missing or very low aerosol signal; similarly as for a) a cloud return is visible around layer 10 at 12:00.

For the presented 30 minute wind measurement period along the east coast of Greenland the 2- $\mu \mathrm{m}$ lidar provided three dimensional wind vectors compared to the LOS winds of the A2D measured at a constant $20^{\circ}$ slant angle. Hence a projection has to be performed. This is done in the geodetic coordinate system by using the vector product of the $2-\mu \mathrm{m}$ wind vector and the mean A2D-LOS unit vector calculated from the aircraft attitude data over the respective observational period. The results of the wind processing chain for the $2-\mu \mathrm{m}$ lidar and the A2D Rayleigh and Mie channel are shown in Figure 2. Strong winds are present in the jet-stream region between 6-10 km and from 12:05 for all of the 
three data sets. Further visible features are a cloud around 12:00 at $5 \mathrm{~km}$ and the wind zone of medium strength between 12:00 and 12:15 reaching from the sea surface up to $2 \mathrm{~km}$. For the A2D wind fields the signal of the internal reference corresponds to a layer index of 0 whereas the sea surface has been detected in layer 18 (Figure 2, middle \& bottom). Due to the absence of thick clouds in a clean atmosphere solely the Rayleigh channel, sensitive to molecular backscatter, is able to provide valid full vertical wind profiles. Layer index 0 corresponds to the mean flight altitude of the Falcon aircraft of $10.4 \mathrm{~km}$. This layer depicts the Doppler frequency of the internal reference which should be equal to zero after correct processing. While layers 1 to 17 contain atmospheric measurements, the ground return or sea surface echo, respectively, was found in layer 18. No valid signal is present below this layer. Strong LOS winds of up to $24 \mathrm{~m} / \mathrm{s}$ are found around layer 5 after 12:05 in the jet stream region. Also close to the sea surface a contrasted region of up to $12 \mathrm{~m} / \mathrm{s}$ stands out from 11:55 to 12:15 being related to a catabatic flow streaming down from the Greenland ice shield.

On the Mie channel white areas in between these layers mark invalid wind measurements due to low SNR, i.e. low aerosol content and hence low particle backscatter. The signal in the region of layer 10 around 12:00 is related to an orographic cloud induced by the above mentioned catabatic flow. This flow is also assumed to have dispersed marine aerosols leading to valid signals in layers 15-17.

Similarities in wind field characteristics between the 2- $\mu \mathrm{m}$ lidar and the A2D Mie channel are apparent and based on the fact that both are targeting aerosol backscatter. Since in

Figure 2 for the A2D Rayleigh and the Mie channel each sampling layer has a vertical thickness of $600 \mathrm{~m}$, an interpretation as altitude scale as used for the $2-\mu \mathrm{m}$ wind field is allowed in the presented case. In the following statistical comparison the $2-\mu \mathrm{m}$ lidar is taken as the truth due to its proven small bias and random error [3].

\section{STATISTICAL COMPARISON}

Due to the different measurement principles and sensitivities of the A2D and 2- $\mu \mathrm{m}$ lidar the data is handled on different spatial and temporal grids. Whereas in the presented case the A2D recorded observations of $18 \mathrm{~s}$ and vertical bin thicknesses of $600 \mathrm{~m}$, it took $32 \mathrm{~s}$ for the 2- $\mu \mathrm{m}$ lidar to get a wind vector profile using a conical scanning technique with $100 \mathrm{~m}$ vertical resolution. For the presented 30 minute case 97 A2D observations are accompanied by 54 observations from the $2-\mu \mathrm{m}$ lidar. The two resulting incongruent grids necessitate an interpolation algorithm enabling a simple bin to bin comparison.

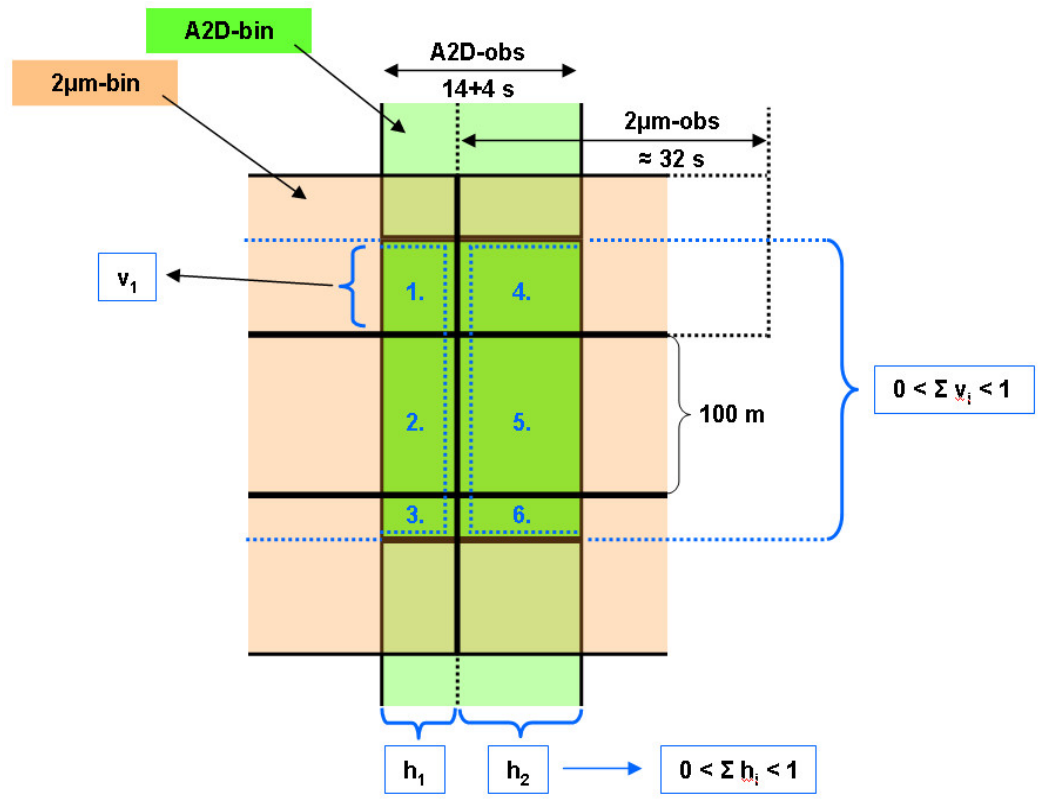

Figure 3. Sketch to visualise the interpolation scheme; for every section of a 2- $\mu \mathrm{m}$ bin (red) covering an A2D bin (green) a weighting $\left(\mathrm{v}_{\mathrm{i}} \cdot \mathrm{h}_{\mathrm{i}}\right)$ is allocated depending on the aerial contribution to the selected A2D bin. Index i names the $2-\mu \mathrm{m}$ bin parts (here 1 to 6 ) contributing to the area of the A2D bin.

Figure 3 shows a sketch to visualize the applied interpolation scheme. In the presented generalized example one A2D bin (darker green, center) is overlaid by six $2-\mu \mathrm{m}$ bins (red). The aim is to derive a wind velocity value from those $2-\mu \mathrm{m}$ bin 
parts (named by index i) covering the A2D bin area. Therefore vertical $\left(\mathrm{v}_{\mathrm{i}} \& \Sigma \mathrm{v}_{\mathrm{i}}=1\right)$ and horizontal $\left(\mathrm{h}_{\mathrm{i}} \& \Sigma \mathrm{h}_{\mathrm{i}}=1\right)$ weighting values are introduced in order to describe the contribution of each of the 6 parts onto the final wind speed $\mathrm{w}_{2 \mu \mathrm{m}}$ which is then determined by:

$$
w_{2 \mu m}=\frac{1}{\sum_{i=1}^{n} h_{i} v_{i}} \sum_{i=1}^{n} w_{i} h_{i} v_{i}
$$

In case of invalid $2-\mu \mathrm{m}$ bins, e.g. due to low atmospheric aerosol content, overlapping an A2D bin the remaining weighting factors are scaled such that the difference to $\Sigma \mathrm{h}_{\mathrm{i}} \cdot \mathrm{v}_{\mathrm{i}}=1$ is compensated. As this approach implies an imbalance in allocated wind speeds, an aerial coverage ratio is also calculated in such cases, which serves as an adjustable threshold to sort out bins for the comparison whose interpolated value is assumed not to be representative anymore. The ratio will be $100 \%$, if all 6 range bins from the $2-\mu \mathrm{m}$ wind lidar are valid but below $50 \%$, if e.g. only bin 1 and 4 are valid. Especially in cases of high vertical gradients in wind speed a low threshold can lead to errors of representativeness, since an A2D wind with a vertical bin extent of more than $500 \mathrm{~m}$ would be compared to a 2- $\mu \mathrm{m}$ wind derived only from the uppermost or lowermost part of the bin. An empirically chosen coverage ratio of around $85 \%$ showed to be an adequate value for the current case study.
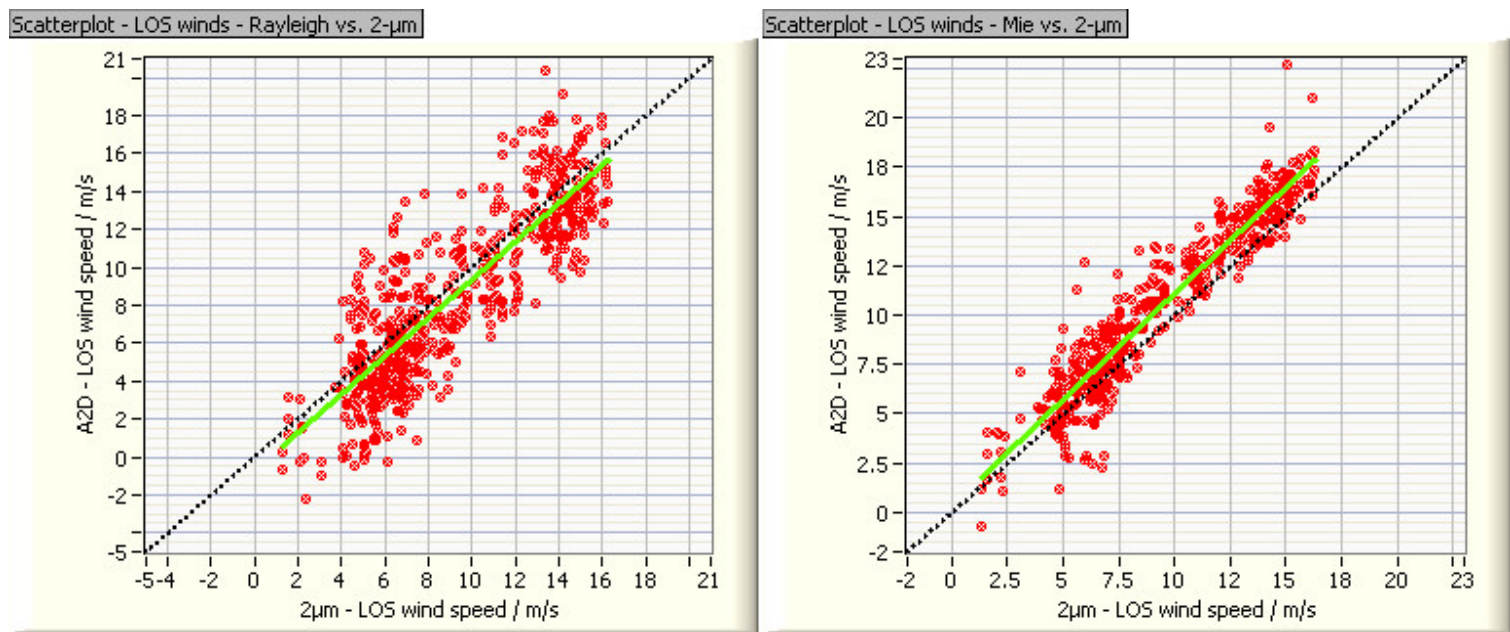

Figure 4. Scatterplots for all bins (red dots) available for comparison within layer 3-17 (atmosphere) processed with the $2^{\text {nd }}$ calibration from 21.09 .2009 and using a coverage ratio of $85 \%$. Also indicated are the linear fits (green) and the ideal $\mathrm{x}=\mathrm{y}$ lines (dashed black)

For comparison only the atmospheric layers 3 to 17 were used due to degraded signals in the A2D near field caused by the overlap inherent to the telescope configuration. Figure 4 shows the resulting scatterplots for A2D winds processed with the $2^{\text {nd }}$ calibration from $21^{\text {th }}$ September 2009. The green line corresponds to a linear fit using the least squares method and the black dashed line constitutes the ideal relation of $\mathrm{x}=\mathrm{y}$. Whereas the comparison of 522 interpolated bins from 2- $\mu \mathrm{m}$ lidar to the A2D-Rayleigh channel leads to a nearly ideal slope of 1.01 with a systematic and random error of $-0.72 \mathrm{~m} / \mathrm{s}$ and $1.91 \mathrm{~m} / \mathrm{s}$, respectively, the comparison to 482 bins from the A2D Mie channel gives a slope of 1.08 and a systematic and random error of $1.06 \mathrm{~m} / \mathrm{s}$ and $1.25 \mathrm{~m} / \mathrm{s}$, respectively. Especially the low random error regarding the Mie channel contributes to the high correlation coefficient of 0.95 , compared to 0.85 with respect to the Rayleigh channel. Hence $\mathrm{r}^{2}$ reaches values $>0.70$, enabling the explanation of at least $70 \%$ of the occurring variance. The random error has first been calculated per layer and then weighted with the number of bins per layer available for comparison before being combined to a mean weighted standard deviation. For the Mie comparison a number of 3 outliers in the A2D winds with values between $40-50 \mathrm{~m} / \mathrm{s}$ have been excluded manually.

Table 2 summarises the results found for comparisons of $2-\mu \mathrm{m}$ winds with winds from the A2D Mie and Rayleigh channels regarding the processing with the $2^{\text {nd }}$ calibration available from the 21.09.2009. The standard deviations of both channels are compliant with the Aeolus requirements. A larger discrepancy of $1.8 \mathrm{~m} / \mathrm{s}$ for the systematic error and of more than $20 \%$ in terms of slope error is found for the Rayleigh channel when applying the $1^{\text {st }}$ calibration for which no 
definite explanation could be found yet. A potential minor error of representativeness due to slightly different atmospheric sampling volumes of the two lidars could be present.

Table 2. Summarised results of the statistical comparisons of A2D Rayleigh and Mie winds to 2- $\mu$ m winds using the $1^{\text {st }}$ calibration from $26^{\text {th }}$ September. Shown are the systematic difference (bias), standard deviation weighted by the number of available bins per respective layer, the correlation coefficient $r$, the slope of the linear fit and the derived slope error.

\begin{tabular}{|c|c|c|}
\hline & Rayleigh & Mie \\
\hline Number of compared bins & 522 & 482 \\
\hline $\mathrm{Bias} / \mathrm{m} / \mathrm{s}$ & -0.72 & 1.06 \\
\hline Standard deviation (weighted) $/ \mathrm{m} / \mathrm{s}$ & 1.91 & 1.25 \\
\hline Correlation $r$ & 0.85 & 0.95 \\
\hline Slope of linear fit & 1.01 & 1.08 \\
\hline Slope error / \% & 1 & 8 \\
\hline
\end{tabular}

\section{SUMMARY}

An overview was given of a DLR airborne campaign operating the A2D instrument in the North Atlantic region in 2009, where a heterodyne and a direct detection Doppler lidar were flown together measuring wind velocity profiles. A new aerial interpolation algorithm has been introduced enabling a bin to bin comparison between winds measured by the 2$\mu \mathrm{m}$ lidar and the A2D. For the comparisons a total number of 522 and 482 points was used for the Rayleigh and the Mie channel, respectively. In a linear regression analysis using the least squares method the slopes of the linear fit straights are found with 1.01 for the Rayleigh channel and 1.08 for the Mie channel. Maximum standard deviations for the Rayleigh channel with $1.91 \mathrm{~m} / \mathrm{s}$ are higher than for the Mie channel with $1.25 \mathrm{~m} / \mathrm{s}$, both compliant with Aeolus requirements. As expected the retrieved values of $r>0.85$ and $r>0.95$, respectively, show a significant positive linear relation between winds measured by the $2-\mu \mathrm{m}$ lidar and A2D. Future improvements mainly aim at correcting for the non-linearity error resulting from A2D response calibrations. Correction for atmospheric temperature differences between calibration and wind measurement as well as for frequency of the single calibration steps via exact measurements by a wavemeter is foreseen.

\section{ACKNOWLEDGEMENT}

Funding for the development of the ALADIN Airborne Demonstrator A2D and performance of campaigns was provided by ESA and DLR. Ulrike Paffrath contributed with crucial work in the processor development. Special thanks go to Engelbert Nagel for his permanently available technical assistance and to the pilots of the DLR flight facility. The authors would like to thank ESA (Anne-Grete Straume, Herbert Nett, Olivier LeRille and Martin Endemann) and Michael Vaughan for their critical reviews and comments which helped to improve the early versions of this paper.

\section{REFERENCES}

[1] ESA European Space Agency, “ADM-Aeolus Science Report,” ESA SP-1311 (2008).

[2] Stoffelen A., Pailleux J., Källen E., Vaughan M., Isaksen L., Flamant P., Wergen W., Andersson E., Schyberg H., Culoma A., Meynart R., Endemann M. and Ingmann P., "The Atmospheric Dynamics Mission for Global Wind Field Measurement," Bull. Amer. Meteor. Soc., 86, 73-87 (2005).

[3] Weissmann M., Busen R., Dörnbrack A., Rahm S. and Reitebuch O., "Targeted Observations with an Airborne Wind Lidar,“ J. Atmos. Oceanic Technol., 22, 1706-1719 (2005).

[4] Durand Y., Chinal E., Endemann M., Meynart R., Reitebuch O. and Treichel R., "ALADIN Airborne Demonstrator: a Doppler Wind Lidar to prepare ESA's ADM-Aeolus Explorer Mission," Proc. SPIE Optics and Photonics, 6296, San Diego, CA, USA, 6296-1D (2006). 
[5] Tan D., Andersson E., de Kloe J., Marseille G.-J., Stoffelen A., Poli P., Denneulin M.-L., Dabas A., Huber D., Reitebuch O., Flamant P., Le Rille O. and Nett H., "The ADM-Aeolus wind retrieval algorithms," Tellus, 60A, 191-205 (2008).

[6] Dabas A., Denneulin M. L., Flamant P., Loth C. and Garnier A., "Correcting winds measured with a Rayleigh Doppler lidar from pressure and temperature effects," Tellus, 60A, 206-215 (2008).

[7] Paffrath U., Lemmerz C., Reitebuch O., Witschas B., Nikolaus I. and Freudenthaler V., "The Airborne Demonstrator for the Direct-Detection Doppler Wind Lidar ALADIN on ADM-Aeolus. Part II: Simulations and Rayleigh Receiver Radiometric Performance,“ J. Atmos. Ocean. Tech., 26, 2516-2530 (2009).

[8] Reitebuch O., Lemmerz C., Nagel E., Paffrath U., Durand Y., Endemann M., Fabre F. and Chaloupy M., "The Airborne Demonstrator for the Direct-Detection Doppler Wind Lidar ALADIN on ADM-Aeolus. Part I: Instrument Design and Comparison to Satellite Instrument,“ J. Atmos. Ocean. Tech., 26, 2501-2515 (2009).

[9] Reitebuch O., Endemann M., Engelbart D., Freudenthaler V., Lehmann V., Lemmerz C., Nagel E., Paffrath U., Rahm S. and Witschas B., "Pre-Launch validation of ADM-Aeolus with an airborne direct-detection wind lidar," Reviewed and Revised Papers of $24^{\text {th }}$ Int. Laser Radar Conference, 41-44 (2008).

[10]Durand Y., Meynart R., Endemann M., Chinal E., Morançais D., Schröder T. and Reitebuch O., "Manufacturing of an airborne demonstrator of ALADIN, the direct detection Doppler wind lidar for ADMAeolus," Proc. SPIE Europe Int. Symp. Remote Sensing, 5984, Bruges, Belgium, 5984-01.

[11] Schröder T., Lemmerz C., Reitebuch O., Wirth M., Wührer C. and Treichel R., "Frequency jitter and spectral width of an injection-seeded Q-switched Nd:YAG laser for a Doppler wind lidar,“ Appl. Phys., B87, 437-444 (2006).

[12] Vieitez M. O., van Duijn E. J., Ubachs W., Witschas B., Meijer A., de Wijn A. S., Dam N. J. and van de Water W., "Coherent and spontaneous Rayleigh-Brillouin scattering in atomic and molecular gases and gas mixtures," Physical Review A 82(4), 043836 (2010).

[13] Witschas B., Vieitez M. O., van Duijn E.-J., Reitebuch O., van de Water W. and Ubachs W., "Spontaneous Rayleigh-Brillouin scattering of ultraviolet light in nitrogen, dry air, and moist air,“ Appl. Opt., 49, 4217-4227 (2010).

[14] Witschas B., "Analytical model for Rayleigh-Brillouin line shapes in air,“ Appl. Opt., 50, 267-270 (2010).

[15] Köpp F., Rahm S. and Smalikho I., "Characterization of Aircraft Wake Vortices by $2-\mu \mathrm{m}$ Pulsed Doppler Lidar," J. Atmos. Oceanic Technol. 21, 194-206 (2003).

[16]Li Z., Lemmerz C., Paffrath U., Reitebuch O. and Witschas B., "Airborne Doppler Lidar Investigation of Sea Surface Reflectance at 355-nm Ultraviolet Wavelength,“ J. Atmos. Oceanic Tech., 693-704 (2010). 